\title{
Design Method Using Thermal Analysis in the Development of Electric Braking Resistor for Railway Carriage
}

\author{
Myung-Jin Chung, ${ }^{1, *}$ \\ ${ }^{1}$ Department of Mechatronics Engineering, Korea Polytechnic University, 237, \\ Sangidaehak-ro, Siheung-si, Gyeonggi-do, Republic of Korea \\ *mjchung@kpu.ac.kr
}

\begin{abstract}
For a train's safe operation, a braking system is necessary to control its velocity easily and fast. A braking system is classified into mechanical braking, which transforms kinetic energy into heat, and electric braking, which transforms power energy into heat. A braking resistor is used to suppress the increased voltage and absorb the regenerative power. Regenerative braking system dissipates the regenerative energy generated by electric braking in the load resistor and suppresses the excess voltage of the power electronics system. In this paper, a method to design the electric braking resistor of a roof-type electric braking system used for railway carriage is proposed by the use of thermal analysis. Through thermal analysis, the shape and arrangement of an element, which is the main part of a braking resistor is designed. The verification of the designed values is conducted by experiments on the developed electric braking resistor. The experimental result for the maximum temperature of the element is $603.8^{\circ} \mathrm{C}$, which deviates $1.3 \%$ from the designed value.
\end{abstract}

Keywords: Design method, thermal analysis, electric braking resistor, railway carriage, computational fluid dynamics, heat transfer

\section{Introduction}

For a train's safe operation, a braking system is necessary to control velocity easily and fast. A braking system is classified into mechanical braking, which transforms kinetic energy into heat, and electric braking, which transforms power energy into heat [1-4]. As an inverter is used as an energy transform device in various industrial areas, circuits embedded with an inverter can be damaged by voltage surge. A braking resistor is used to suppress the voltage surge and absorb the regenerative power. In inverter operation, the inertia energy of the motor and load is transformed to electric energy by speed reduction and is regenerated to an inverter [5-7]. By dissipation of regenerated energy into heat, the efficiency of the speed reduction by inverter is increased. Regenerative braking system dissipates the regenerative energy (regenerative voltage) generated by the electric braking in the load resistor and suppresses the excess voltage of the power electronics system. This system is necessary for the control of train velocity, and the dissipation of regenerative power generated by the velocity reduction of high-speed trains.

Many researches related with the development of the regenerative braking system for electric vehicles and high-speed trains are proposed [8-13]. Regenerative braking system used in high-speed trains is classified into a roof type and an under type according to the arranged position at train. The roof-type regenerative braking system is 
more popular than the under type because of easy installation, small space, light weight, and high efficiency of natural cooling.

In this paper, a method to design the electric braking resistor of a roof-type electric braking system used for railway carriage is proposed by the use of thermal analysis. By thermal analysis, the shape and arrangement of an element which is the main part of an electric braking resistor is designed. The verification of the designed values is conducted by experiments with a developed electric braking resistor.

\section{Configuration of Roof Type Regenerative Braking System}

A roof-type regenerative braking system is positioned on the upper side of the railway carriage as shown in Figure 1. In the roof-type regenerative braking system, the inertia energy of motor and load is transformed to electric energy, and is regenerated in the inverter as shown in Figure 2. This regenerated energy is dissipated to heat, so the efficiency of speed reduction by inverter is increased.

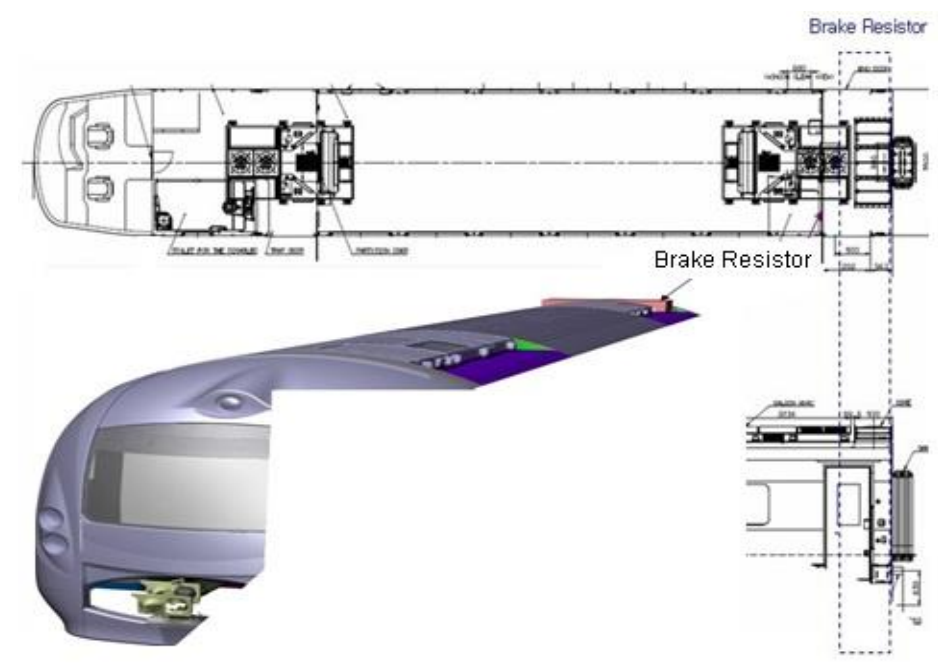

Figure 1. Arrangement of Roof-type Regenerative Braking System in the Railway Carriage

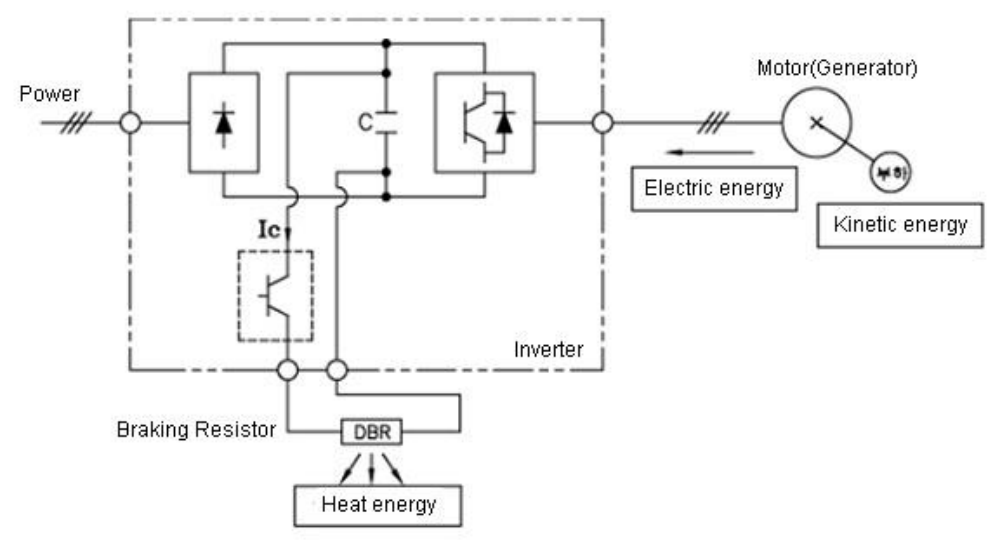

Figure 2. Schematic Diagram of the Operation of a Roof-type Regenerative Braking System 
The electric braking resistor of a roof-type regenerative braking system consists of elements, an out frame to separate the resistor from the outside, and insulators to insulate the elements from the out frame as shown in Figure 3. In this configuration, the elements have a sheet plate shape to release the heat generated by regenerative braking and to increase resistance. High resistance can be achieved by a serial welding of each element.

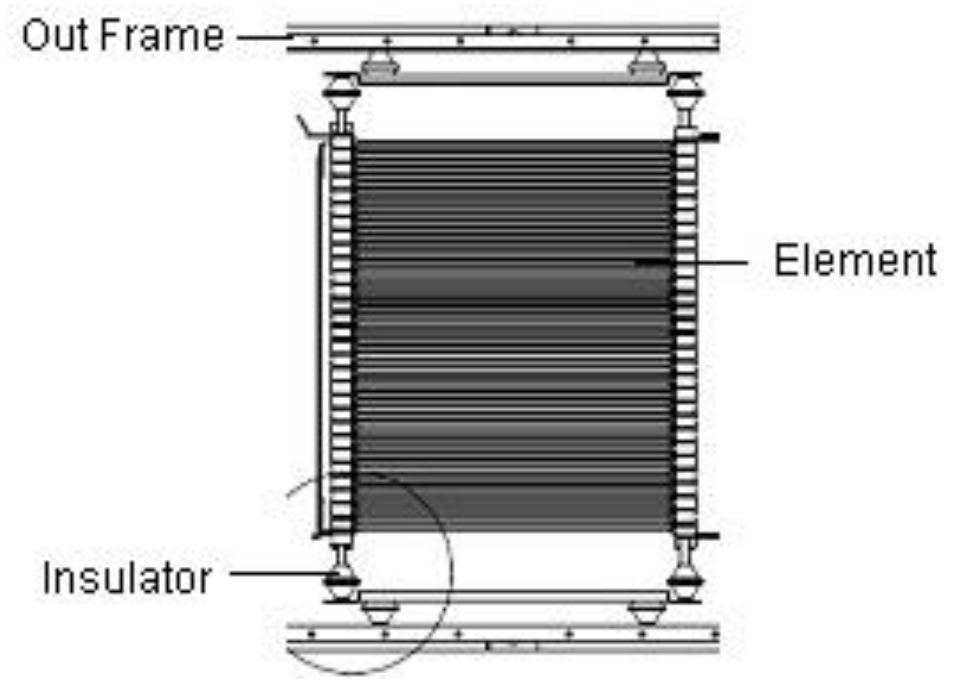

Figure 3. Configuration of Electric Braking Resistor

\section{Requirement of Electric Braking Resistor}

The requirement of the electric braking resistor used for roof-type regenerative braking system is to preserve the efficiency of regenerative braking to minimize velocity reduction time. Thus, it is necessary that the heat generated by regenerative braking is dissipated and the temperature rise in a braking system is minimized. The heat generation by regenerative braking depends on braking conditions such as deceleration, velocity, and inertia by train mass. In this work, a condition generated by the regenerative braking of high-speed train is used as a design requirement. As shown in Figure 2, electric energy is generated by regenerative braking and feed to invertor. This electric energy can be described as standard power for the design and experiment of the electric braking resistor as shown in Figure 4.

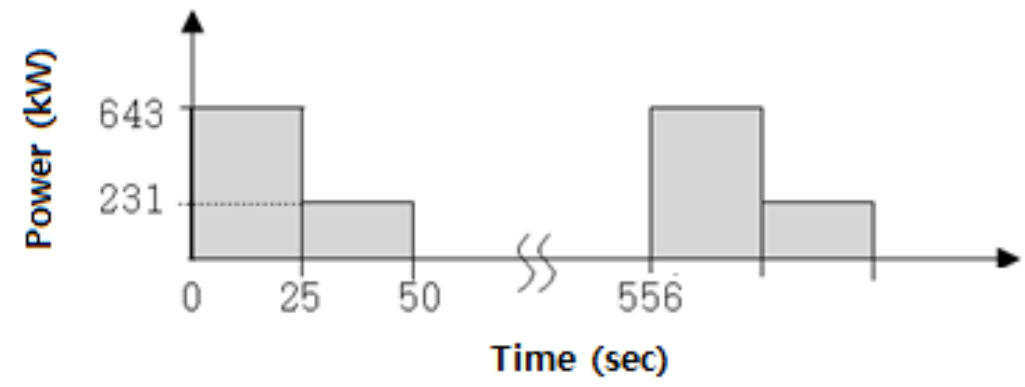

Figure 4. Standard Power Equivalent to Electric Energy Generated by Regenerative Braking 
The requiring specifications of the electric braking resistor used for roof type regenerative braking system are listed in Table 1.

Table 1. Required Specifications of the Electric Braking Resistor

\begin{tabular}{ccc}
\hline Item & Value & Unit \\
\hline Max. supply voltage & DC 4,000 & Volt \\
Resistance & 7.5 & $\Omega$ \\
Max. temperature & 600 & ${ }^{\circ} \mathrm{C}$ \\
\hline
\end{tabular}

\section{Thermal Analysis}

Thermal analysis is used to design the shape and arrangement of the element which is the main part of the electric braking resistor used for the dissipation of the heat generated by the regenerative braking. In the thermal analysis, the temperature rise of elements acting as a resistor is calculated according to current flow induced by the voltage generated in the regenerative braking process.

\subsection{Resistance Characteristics}

The shape of the electric braking resistor used for roof-type regenerative braking system is determined by elements connected with series or series-parallel according to heat dissipation and structure. The number of elements is determined to satisfy the required resistance. Figure 5 shows the shape of a single element. Resistance is changed according to the temperature of element, and is increased according to the rise of temperature. Resistance at the normal temperature of $20^{\circ} \mathrm{C}\left(\mathrm{R}_{20}\right)$ and resistance at the temperature of $\mathrm{t}^{\circ} \mathrm{C}\left(\mathrm{R}_{\mathrm{t}}\right)$ is described in Equations 1 and 2.
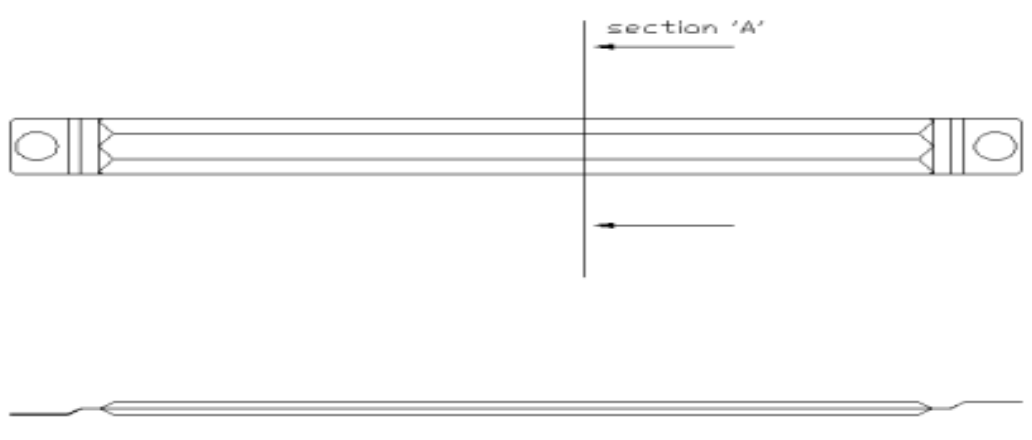

Figure 5. Shape of a Single Element Used for Resistor

$$
\begin{aligned}
& R_{20}=\rho \frac{L}{A} \\
& R_{t}=R_{20}\left[1+\alpha_{20}(t-20)\right]
\end{aligned}
$$

where, $\rho$ is the specific resistance of element, $\mathrm{L}$ is the total length of element, $\mathrm{A}$ is the area of element, $\alpha_{20}$ is the resistance temperature coefficient of element at $20^{\circ} \mathrm{C}$. 
Resistance is increased by latent heat generated by supplied power. This resistance increment prevents the power inflow to an element.

\subsection{Thermal Characteristics}

The power supplied to element induces heat transfer such as conduction, convection, and radiation. The temperature of element is determined by latent heat according to the difference of supplied heat and transferred heat. Heat transfer is conducted as combined form of conduction, convection, and radiation according to the shape of element or environmental condition. Heat generated by conduction $\left(\mathrm{Q}_{\mathrm{k}}\right)$, convection $\left(\mathrm{Q}_{\mathrm{c}}\right)$, and radiation $\left(\mathrm{Q}_{\mathrm{r}}\right)$ is described as Equations 3, 4, and 5, respectively.

$$
\begin{aligned}
& Q_{k}=-k A \frac{d T}{d x} \\
& Q_{c}=h A\left(T_{\text {suf }}-T_{d}\right) \\
& Q_{r}=\varepsilon \sigma F A\left(T_{\text {suf }}^{4}-T_{d}^{4}\right)
\end{aligned}
$$

where, $\mathrm{k}$ is the conduction coefficient, $\mathrm{A}$ is the area of element, $\mathrm{h}$ is the convection coefficient, $\mathrm{T}_{\text {suf }}$ is the surface temperature of element, $\mathrm{T}_{\mathrm{d}}$ is the temperature of boundary, $\varepsilon$ is the emissivity, $\sigma$ is the Stefan-Boltzmann constant, and F is the shape factor.

\subsection{Resistor Materials}

The requirement of resistor material is that the property of resistor should be maintained in case of high temperature rise and resistance should not be sensitive on temperature. In general, a series of 310 made by Kanthal and Thyssenkrupp is used as resistor material.

\subsection{Design Variables}

The total resistance of resistor $\left(\mathrm{R}_{\text {res }}\right)$ and maximum temperature of resistor $\left(T_{\max }\right)$ according to input condition are the main constraints in the design of an element. The design variables affecting these constraints are element shapes such as height (h), thickness (t), length (l), and series connected number (n) as shown in Figure 6.

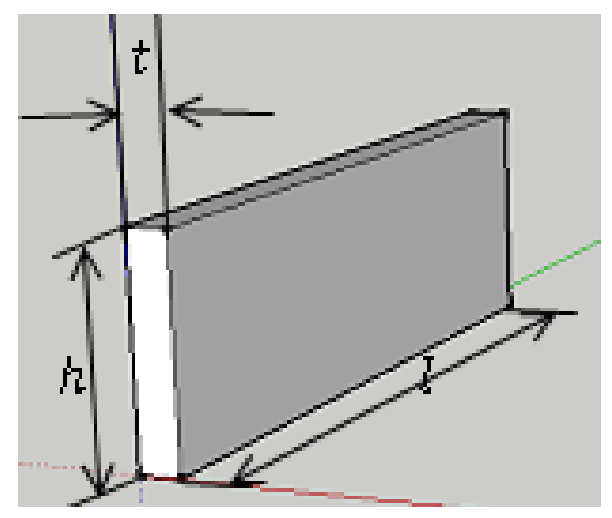

Figure 6. Design Variables in the Element Shape 
The total resistance of a resistor can be calculated with the design variables of an element shape as in Equation 6.

$$
R_{r e q}=\rho \frac{n l}{h t}
$$

In Equation 6, the ratio of total length to area is calculated as Equation 7. By fixing the area, the design variable is simplified.

$$
\frac{n l}{h t}=\frac{R_{r e q}}{\rho}
$$

\subsection{Thermal Analysis Model}

The temperature of a resistor is determined by heat generated by the element itself and heat dissipated according to the gap of the element related with the cooling method. In this analysis, a natural cooling condition is used for the element. Thermal analysis is conducted with computational fluid dynamics (CFD) software. The analysis model is simplified to two-dimension (2-D) as shown in Figure 7.
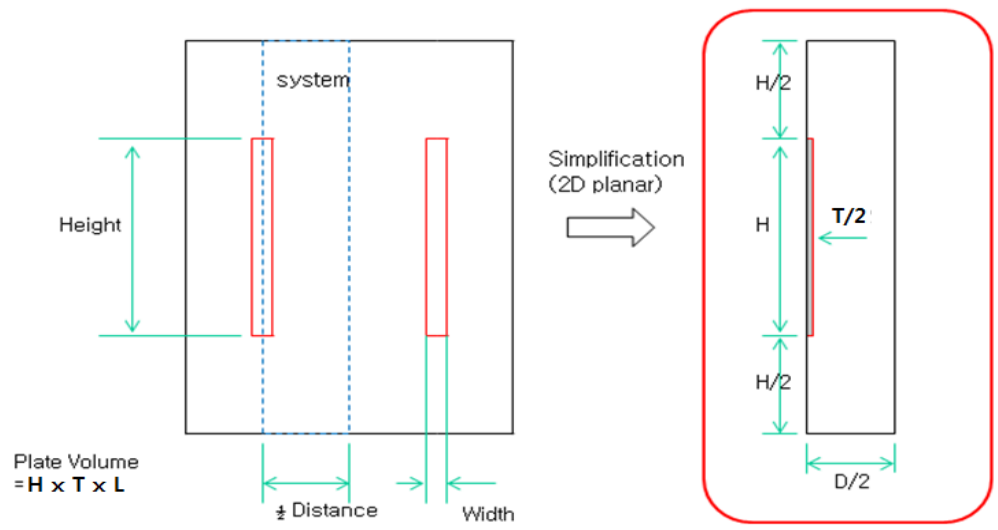

(a) Simplified Model

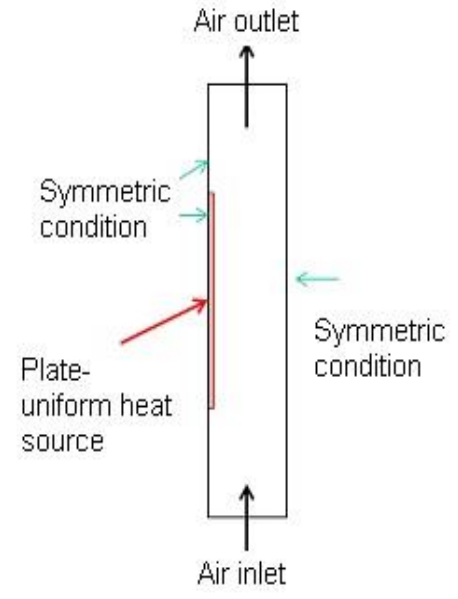

(b) Boundary condition

Figure 7. Thermal Analysis Model 


\section{Results and Discussion}

To satisfy the design specifications of the electric braking resistor used for roof-type regenerative braking system as listed in Table 1, the shape and arrangement of element are designed with thermal analysis and design values as listed in Table 2.

Table 2. Designed Values of the Electric Braking Resistor

\begin{tabular}{ccc}
\hline Item & Value & Unit \\
\hline Element thickness & 0.6 & $\mathrm{~mm}$ \\
Element height & 45 & $\mathrm{~mm}$ \\
Element length & 500 & $\mathrm{~mm}$ \\
Space between elements & 10 & $\mathrm{~mm}$ \\
Total number of elements & 465 & EA \\
\hline
\end{tabular}

In the design process, thermal analysis is conducted with CFD software, and the simplified 2-D analysis model shown in Figure 7 is used. The characteristic of element heating by standard power is shown in Figure 4 and heat dissipation by heat transfer of the element according to time step is analyzed as shown in Figure 8.

The temperature of the element is increased by heat supply during the power applying time, and the temperature of the element is decreased by heat dissipation during the remaining time.

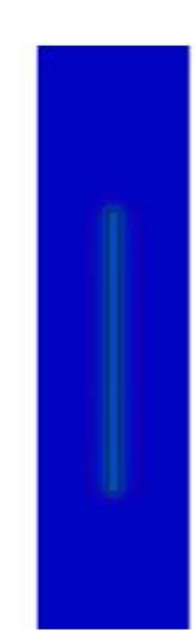

(a) $t=0$ sec

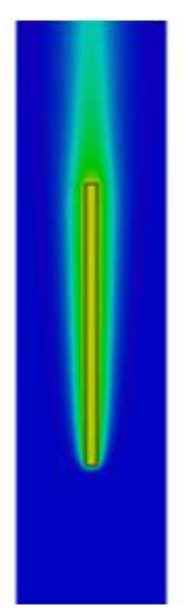

(b) $t=20 \mathrm{sec}$

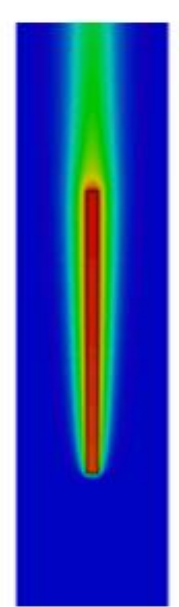

(c) $t=50 \mathrm{sec}$

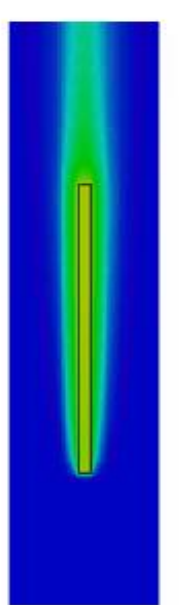

(d) $t=200 \mathrm{sec}$
$\mathrm{T}(\mathrm{C})$

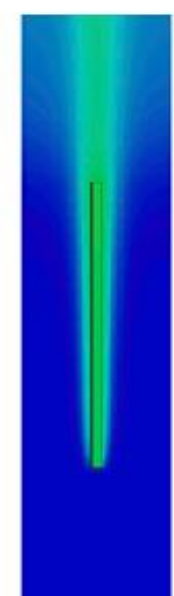

600

450

300

150

Figure 8. Heating Characteristics of the Element According to Time Step 
In Figure 8, the maximum temperature of the element during the time step can be calculated. The trend of the temperature rise according to the shape (thickness and height) of the element is analyzed by thermal analysis as shown in Figure 9.
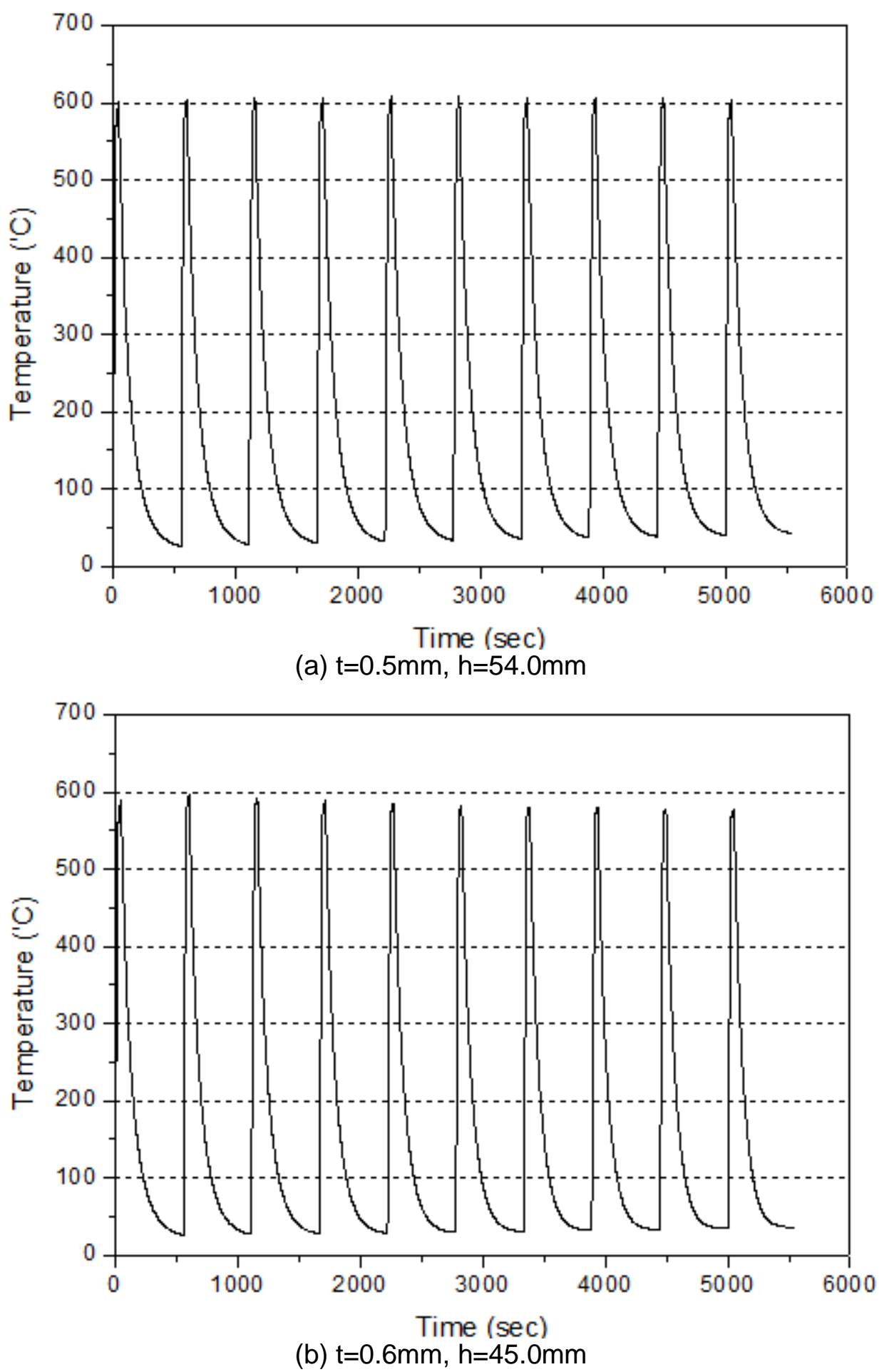


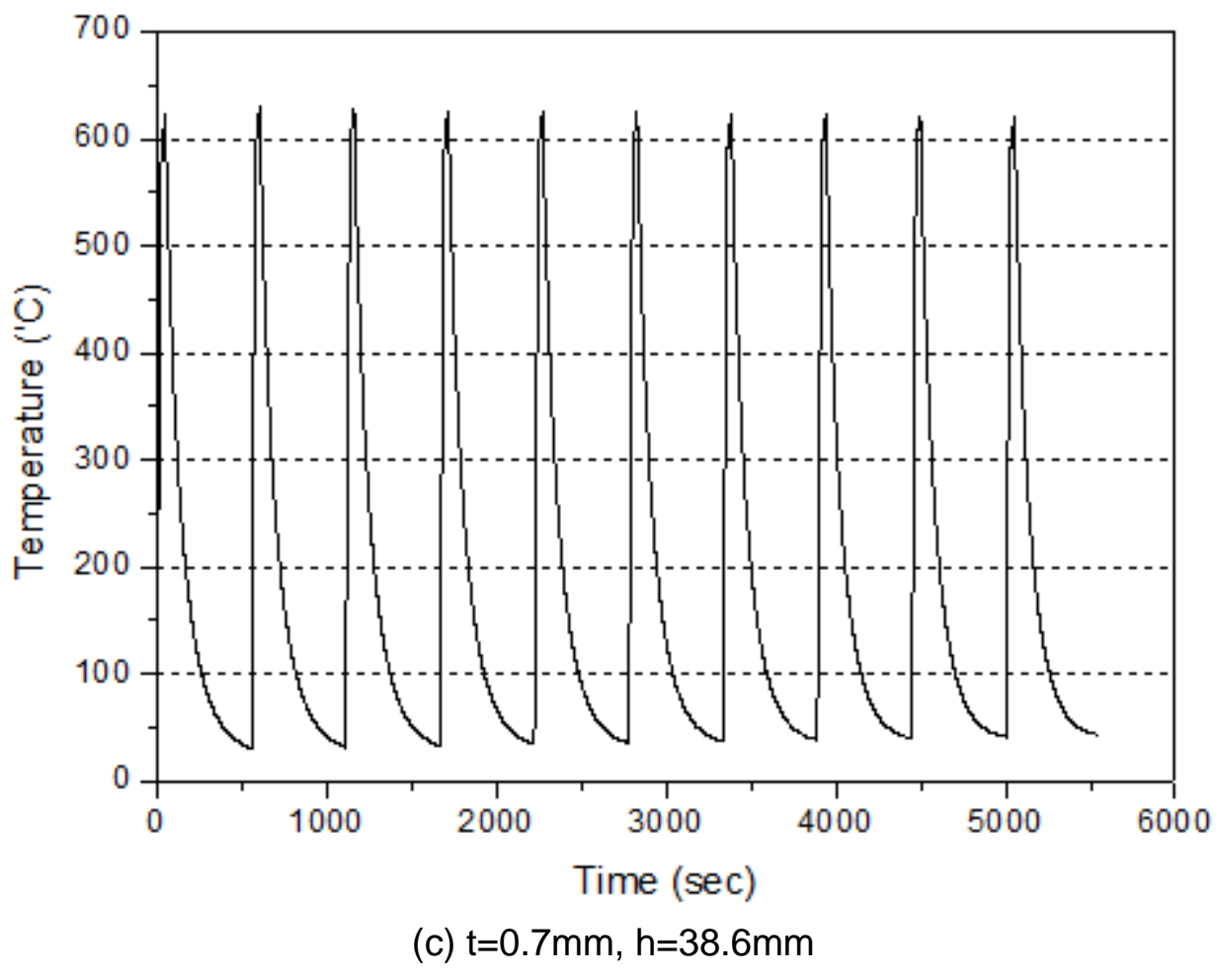

\section{Figure 9. Trend of the Temperature Rise According to Shape (Thickness and Height) of the Element}

Maximum temperature rise is calculated as $607.3^{\circ} \mathrm{C}$ in Figure 9 (a), $596.0^{\circ} \mathrm{C}$ in Figure 9 (b), and $629.0^{\circ} \mathrm{C}$ in Figure 9 (c). From this thermal analysis, the designed value for the shape of the element is a thickness of $0.6 \mathrm{~mm}$ and a height of $45.0 \mathrm{~mm}$.

The electric braking resistor is manufactured with the designed value of the element, while the experiment is conducted to verify the values designed by thermal analysis. The manufactured electric braking resistor and experimental setup are shown in Figure 10 and Figure 11, respectively. Temperature rise is measured using the thermal imager shown in Figure 11. The verification of designed values is conducted by experiments on the developed electric braking resistor. Figure 12 shows the maximum temperature distribution at the measuring position of the element during the cycle time step. The maximum temperature rise of the element is measured as $603.8^{\circ} \mathrm{C}$ as listed in Table 3 , which deviates $1.3 \%$ from the designed value.

\section{Conclusions}

In this paper, a method to design the electric braking resistor of a roof-type regenerative braking system used for railway carriage by the use of 2-D thermal analysis is proposed. By thermal analysis, the shape and arrangement of an element, which is the main part of an electric braking resistor, is designed. 


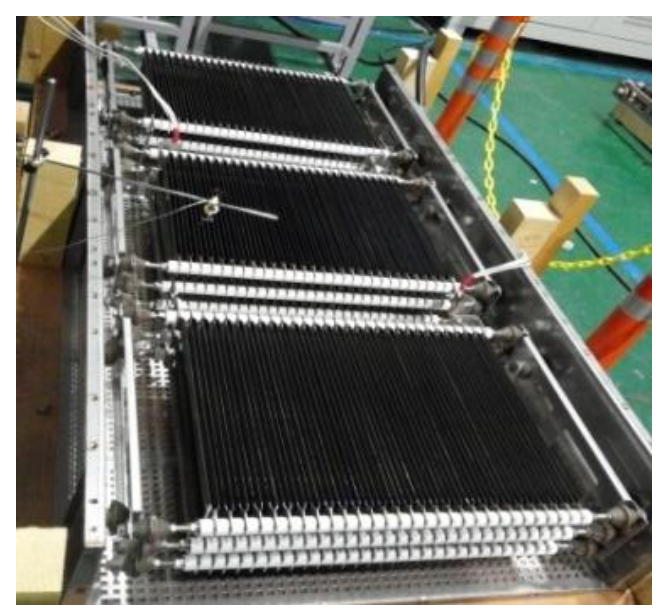

Figure 10. Manufactured Electric Braking Resistor

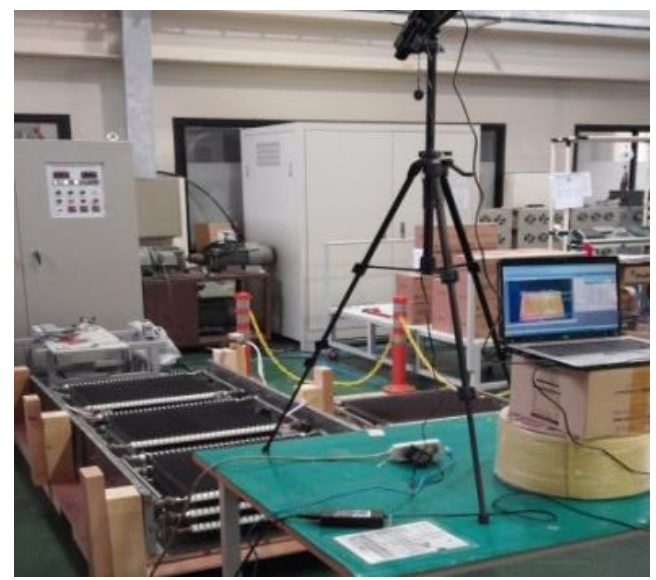

Figure 11. Experimental Setup having the Thermal Imager

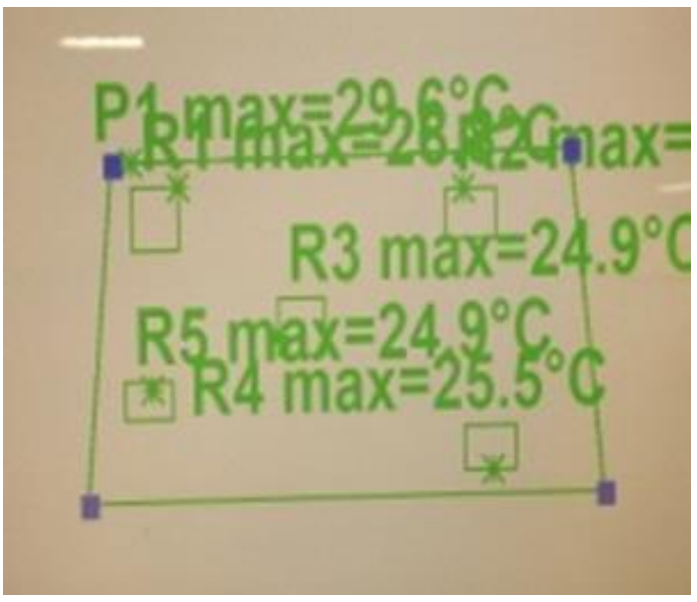

(a) Room temperature

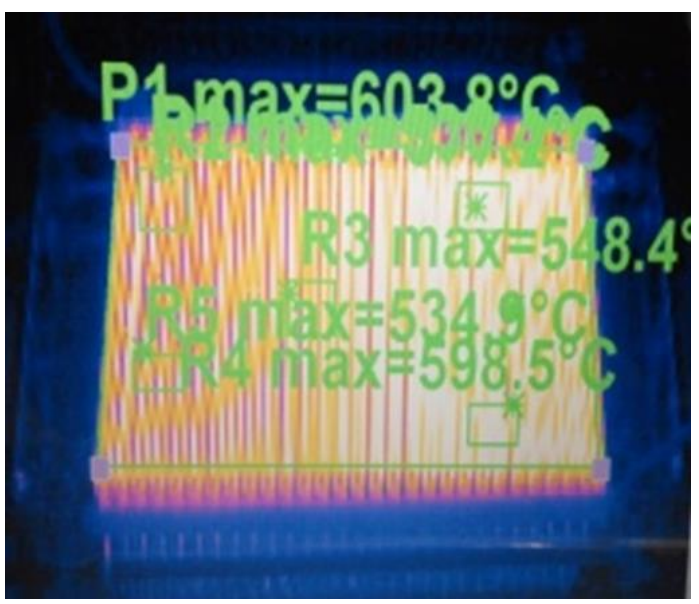

(b) Full-heated temperature

Figure 12. Maximum Temperature Distribution at the Measuring Position of the Element During the Cycle Time Step 


\section{Table 3. Maximum Temperature Rise at the Measuring Position of the Element during the Cycle Time Step}

\begin{tabular}{cccccccc}
\hline $\begin{array}{c}\text { Measuring } \\
\text { position }\end{array}$ & $\mathrm{R} 1$ & $\mathrm{R} 2$ & $\mathrm{R} 3$ & $\mathrm{R} 4$ & $\mathrm{R} 5$ & Air & $\begin{array}{c}\text { Maximum } \\
\text { value }\end{array}$ \\
\hline Temperature $\left({ }^{\circ} \mathrm{C}\right)$ & 528.8 & 588.1 & 560.9 & 603.8 & 523.3 & 26.5 & 603.8 \\
\hline
\end{tabular}

The verification of the designed values is conducted by experiments with developed electric braking resistor. From the verification, the experimental result for the maximum temperature rise of the element is measured as $603.8^{\circ} \mathrm{C}$, which deviates $1.3 \%$ from the designed value. It is concluded that the design method using the thermal analysis is applicable in the development of the electric braking resistor.

\section{Acknowledgements}

This work was supported by the National Research Foundation of Korea Grant funded by the Korean Government (31Z20130012987).

\section{References}

[1] X. M. Huang and G. B. Ning, "Study on Mechanical Braking System Development Method and Validation for Electric Vehicles", Proceedings of the 3rd International Conference on Advanced design and manufacturing engineering, Anshan, China, (2013) July 13-14.

[2] K. Teramoto, K. Ohishi, S. Makishima, K. Uezono and S. Yasukawa, "Cooperative Control of Regenerative Brake and Mechanical Brake for a Two Coach Train", Proceedings of the IECON 2012 - 38th Annual Conference on IEEE Industrial Electronics Society, Montreal, Canada, (2012) October 25-28.

[3] H. S. Lee, S. G. Baek, K. M. Kwon and G. D. Kim, "Study for the Relations between Electric Multiple Unit and Energy Storage System", Proceedings of the 2011 Autumn Conference \& Annual Meeting of the Korean Society for Railway, Jeju, Korea, (2011) October 20-22.

[4] J. S. Huh, B. W. Kang, H. S. Shin and J. C. Kim, "The Transactions of the Korean Institute of Electrical Engineers", vol. 59, (2010), pp. 12.

[5] G. A. Gonzalez, R. Palacin and P. Batty, "Energy Conversion and Management", vol. 75, (2013).

[6] C. J. Youn, M. G. Noh and E. J. Lee, "The Transactions of the Korean Institute of Electrical Engineers", vol. 62, (2013), pp. 3.

[7] G. Y. Zhang and Q. Z. Li, “Applied Mechanics and Materials”, vol. 380/384, (2013).

[8] M. J. Chung and Y. J. Kim, "Design of Roof Type Dynamic Braking Resistor for Railway Carriage by using Thermal Analysis", Proceedings of the 2014 International Workshops, Jeju, Korea, (2014) April 15-18.

[9] J. F. Han, J. Tao, H.J. Lu and D. H. Xin, "Development and Prospect of Regenerative Braking Technology of Electric Vehicles", Proceedings of the International Conference on Renewable Energy and Environmental Technology, Jilin, China, (2013) September 21-22.

[10] L. Xu, J. P. Wang, Y. Bai and G. L. Hu, "Adaptive Robust Control for Driving and Regenerative Braking of Electric Vehicle", Proceedings of the 2013 3rd International Conference on Electrical Engineering and Energy Sciences, Jinan, China, (2013) November 29-30.

[11] D. A. Nicola, M. A. Rosen, C. A. Bulucea and C. Brindusa, "Journal of Rail and Rapid Transit", vol. 224, (2010), pp. 3.

[12] P. Suntharalingam, J. T. Economou and K. Knowles, "Effect on Regenerative Braking Efficiency with Deceleration Demand and Terrain Condition", Proceedings of the 5th International Conference on Power Electronics, Machines and Drives Brighton, United Kingdom, (2010) April 19-21.

[13] H. M. Lee, G. D. Kim and S. H. Park, "A Study on Pressure Control Method of Train Brake System", Proceedings of the 2008 Spring Conference \& Annual Meeting of the Korean Society for Railway, Daigu, Korea, (2008) June 12-13. 


\section{Author}

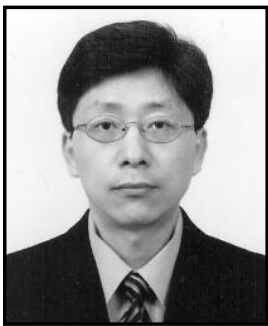

Myung Jin Chung, received the M.S. in Production Engineering (1991) and a PhD in Mechanical Engineering (2002) from the Korea Advanced Institute Science and Technology. Now he is a professor in the Mechatronics Department of the Korea Polytechnic University in Korea. His current research interests include the control of highprecision positioning system and semiconductor manufacturing system. 